\title{
Safety, Tolerability and Clinical Effects of a Rapid Dose Titration of Subcutaneous Treprostinil Therapy in Pulmonary Arterial Hypertension: A Prospective Multi-Centre Trial
}

\author{
Ekkehard Grünig ${ }^{a}$ Nicola Benjamin ${ }^{\mathrm{a}}$ Tobias J. Lange ${ }^{\mathrm{b}} \quad$ Ulrich Krueger $^{\mathrm{c}}$ Hans Klose $^{\mathrm{d}}$ \\ Claus Neurohr $^{\mathrm{e}}$ Heinrike Wilkens ${ }^{f}$ Michael Halank ${ }^{g}$ Hans-Jürgen Seyfarth ${ }^{\mathrm{h}}$ Matthias Held ${ }^{\mathrm{i}}$ \\ Andrew Traube $\quad$ Michelle Pernow ${ }^{j} \quad$ E. Robert Grover ${ }^{j} \quad$ Benjamin Egenlaufa Felix Gerhardt ${ }^{k, I}$ \\ Thomas Viethen $^{k, I}$ Stephan Rosenkranzk, I

\begin{abstract}
${ }^{a}$ Centre for Pulmonary Hypertension, Thorax Clinic at the University of Heidelberg, Heidelberg, ${ }^{b}$ Department of Internal Medicine II, University Medical Centre Regensburg, Regensburg, 'Department of Cardiology, Hospital Niederrhein, Duisburg, d Department of Pneumology, University of Hamburg, Hamburg, e Department of Pneumology, University of Munich, Munich, fDepartment of Pneumology, University of Homburg, Homburg, Leipzig, and 'Mission Medical Hospital, Center of Pulmonary Hypertension and Pulmonary Vascular Disease, Department of Internal Medicine, Würzburg, Germany; 'United Therapeutics Europe Limited, Chertsey, UK; kDepartment of Cardiology, University Hospital Cologne, and 'Cologne Cardiovascular Research Center (CCRC),
\end{abstract} \\ gDepartment of Pneumology, University of Dresden, Dresden, h'Department of Pneumology, University of Leipzig, \\ University of Cologne, Cologne, Germany
}

\section{Key Words}

Treprostinil · Pulmonary arterial hypertension ·

Subcutaneous infusion

\begin{abstract}
Background: Subcutaneous treprostinil has dose-dependent beneficial effects in patients with severe pulmonary arterial hypertension, but adverse effects like infusion site pain can lead to treatment discontinuation. Objectives: The objective of this study was to evaluate safety, tolerability and clinical effects of a rapid up-titration dosing regimen of subcutaneous treprostinil using proactive infusion site pain management. Methods: Effects of rapid up-titration dosing regimen on tolerability and clinical parameters were evaluated in this 16-week, open-label multi-centre study. Results: Thirty-nine patients with idiopathic or heritable pulmonary
\end{abstract}

arterial hypertension on stable treatment with oral pulmonary arterial hypertension-approved drugs (90\% on dual combination therapy) were included. Patients achieved a median treprostinil dosage of $35.7 \mathrm{ng} / \mathrm{kg} / \mathrm{min}$ after 16 weeks. A good overall safety profile was demonstrated with 3 patients (8\%) withdrawing due to infusion site pain, which occurred in $97 \%$ of patients. After 16 weeks, median 6-min walking distance, cardiac index, pulmonary vascular resistance, and tricuspid annular plane systolic excursion improved. Conclusions: Rapid up-titration of subcutaneous treprostinil was well tolerated, achieving a clinically effective dose associated with improvement of exercise capacity and haemodynamics after 16 weeks. A rapid dose titration regimen and proactive infusion site pain management may improve the handling of this therapy and contribute to better treatment outcome.

(c) 2016 S. Karger AG, Basel

\section{KARGER}

E-Mail karger@karger.com

www.karger.com/res
(C) 2016 S. Karger AG, Basel

0025-7931/16/0926-0362\$39.50/0
Ekkehard Grünig, MD

Centre for Pulmonary Hypertension

Thorax Clinic at University of Heidelberg

Röntgenstrasse 1, DE-69126 Heidelberg (Germany)

E-Mail ekkehard.gruenig@med.uni-heidelberg.de 


\section{Introduction}

Pulmonary arterial hypertension (PAH) is a rare, lifethreatening condition that is characterised by a progressive increase in pulmonary vascular resistance (PVR), resulting in chronic right heart failure and premature death. The loss of endogenous prostacyclin plays an important role in the pathogenesis of PAH. Prostacyclin has vasodilatory, anti-proliferative, anti-inflammatory and antithrombotic properties and is therefore an important target substance in PAH-specific therapy [1]. Epoprostenol was the first specific therapy approved for the treatment of PAH, after showing a positive effect on survival [2]. Epoprostenol is chemically unstable with a short biological half-life of 3-5 min, and must be continuously administered by intravenous (IV) infusion using an external pump and indwelling central venous catheter.

Treprostinil, which can be administered by either subcutaneous (SC) or IV infusion, has improved stability with a terminal elimination half-life of $\sim 4 \mathrm{~h}[3]$. A permanent central venous catheter can be avoided by using SC therapy. The medication is continuously administered via a micro-infusion pump using a small-bore catheter and SC cannula which can be self-inserted by the patient. Treatment with SC treprostinil has been shown to improve exercise capacity, symptoms and haemodynamics in patients with PAH in a dose-dependent manner [4], and may improve long-term outcome [5-7]. Local adverse reactions, including infusion site pain, mild bleeding and swelling, can lead to discontinuation of treatment $[5,6]$ and may cause a slow and reluctant dose titration, prolonging the time until treatment is clinically effective. There is, however, no apparent correlation between local adverse reactions and treprostinil dose rate $[3,8]$. By contrast, rapid dose escalation has been reported to cause less frequent site pain ( 58 vs. $82 \%, \mathrm{p}=0.04$ ) and a significantly greater improvement of 6 -min walk distance $(6 \mathrm{MWD}$; $\mathrm{p}=0.03$ ) compared with slow dose escalation [3]. Treprostinil dose rate has also been found to be an independent prognostic on-treatment predictor of survival in a retrospective analysis of 811 patients treated with SC treprostinil [9]. A slow dose titration is therefore a potential cause of sub-therapeutic dosages [10], which may provoke premature discontinuation of treatment. A thorough medical management of SC treprostinil therapy, including multidisciplinary patient support and proactive infusion site pain management, is necessary to achieve a clinically effective dosing regimen [10]. Importantly, infusion site pain can be minimised by avoidance of infusion site replacement until clinically indicated. A rapid treatment initiation of epoprostenol has already been shown to significantly improve haemodynamics and clinical outcome compared to a slow titration regimen $[11,12]$.

Up to now, a rapid dosing regimen of treprostinil has only been investigated in a small group of 12 patients [3]. It is not clear whether this regimen, together with a proactive approach to infusion site pain management, can be well tolerated and effective in a larger patient cohort. Therefore, the aim of this study was to investigate prospectively the safety and tolerability of a rapid dose titration regimen together with proactive infusion site management of SC treprostinil in a larger cohort of patients with severe PAH. Furthermore, the clinical effects after a treatment period of 16 weeks were to be evaluated.

\section{Materials and Methods}

\section{Study Design}

This was an open-label, single-territory, multi-centre study designed to evaluate the safety, tolerability and clinical effects of a rapid dose titration regimen of SC treprostinil in subjects with severe PAH.

\section{Patients/Setting}

Subjects were either treatment naïve or receiving an approved endothelin receptor antagonist (ERA) and/or an approved phosphodiesterase (PDE)-5 inhibitor for at least 60 days and maintained on a stable dose for at least 30 days prior to providing informed consent. Thirty-nine patients were enrolled across 10 centres throughout Germany from 16 April 2012 to 20 March 2014 to ensure a minimum of 30 completing patients [6]. Thirty completing patients were believed to be the minimum requirement to show tolerance to the rapid titration regimen. The main entry criteria for the study are summarised in table 1.

\section{Enrolment and Treprostinil Treatment}

SC treprostinil was initiated on an in-patient basis (minimum of $72 \mathrm{~h}$ ) and under medical supervision at approximately $2 \mathrm{ng} / \mathrm{kg} /$ min with dose increments of $1-2 \mathrm{ng} / \mathrm{kg} / \mathrm{min}$ approximately every $12 \mathrm{~h}$ according to tolerability. The length of hospital stay was determined by subject competency to administer SC treprostinil using a micro-infusion pump (Crono 5; Canè Medical Technology), coupled with either the Cleo (Smiths Medical) or Quickset (Medtronic) infusion set. The SC infusion cannula remained in situ for as long as clinically appropriate because infusion site pain has been shown to diminish over $\sim 5$ days following the insertion of each new cannula [7]. To avoid regular insertion site changes, site pain was managed by proactive application of topical and systemic analgesics, and patients were taught how to maintain a sterile site.

Following discharge from hospital, dose increases of 1-2 ng/ $/ \mathrm{kg} /$ min were permitted every $24 \mathrm{~h}$. Once a dose rate of $20 \mathrm{ng} / \mathrm{kg} / \mathrm{min}$ had been achieved, the dose increments could be up to $4 \mathrm{ng} / \mathrm{kg} / \mathrm{min}$ separated by at least $24 \mathrm{~h}$ based on tolerability. The aim was to achieve a target dose of 10,20 and $30 \mathrm{ng} / \mathrm{kg} / \mathrm{min}$ by the end of weeks 1,4 and 12, respectively, and a dose rate by the end of 16 weeks that achieved and maintained the pre-defined treatment goals, as follows: 
Table 1. Main inclusion and exclusion criteria

\begin{tabular}{|c|c|}
\hline Inclusion criteria & Exclusion criteria \\
\hline 1 Minimum 18 years of age and written informed consent & 1 Pregnant or lactating \\
\hline 2 Weight at least $40 \mathrm{~kg}$ and body mass index less than 40 & $\begin{array}{l}2 \text { Received epoprostenol, treprostinil, IV iloprost, or } \\
\text { beraprost within } 30 \text { days prior to screening }\end{array}$ \\
\hline $\begin{array}{l}3 \text { Using two effective forms of contraception required for females, } \\
\text { and males to use a condom throughout the study and for } 64 \text { days } \\
\text { following treatment cessation }\end{array}$ & $\begin{array}{l}3 \text { Previous intolerance or significant lack of efficacy to } \\
\text { treatment with prostacyclin or prostacyclin analogues }\end{array}$ \\
\hline 4 Diagnosed with symptomatic idiopathic or heritable PAH & $\begin{array}{l}4 \text { Any disease associated with pulmonary hypertension or } \\
\text { an atrial septostomy }\end{array}$ \\
\hline $56 \mathrm{MWD}$ at least 150 and no more than $550 \mathrm{~m}$ & 5 WHO-FC IV \\
\hline $\begin{array}{l}6 \text { Treatment naïve or receiving an approved PDE- } 5 \text { inhibitor and/ } \\
\text { or an approved ERA for at least } 60 \text { days and on a stable dose for } \\
\text { at least } 30 \text { days prior to screening }\end{array}$ & 6 Uncontrolled sleep apnoea \\
\hline $\begin{array}{l}7 \text { Optimally treated with conventional pulmonary hypertension } \\
\text { therapy with no changes for at least } 14 \text { days prior to screening }\end{array}$ & $\begin{array}{l}7 \text { AST and ALT more than } 3 \text { times the upper limit of the } \\
\text { laboratory reference range and/or an international } \\
\text { normalised ratio more than } 3 \text { units at screening }\end{array}$ \\
\hline $\begin{array}{l}8 \text { Right heart catheterisation conducted within } 8 \text { weeks prior to or } \\
\text { during the screening period with: } \\
\text { a Mean pulmonary artery pressure at least } 25 \mathrm{~mm} \mathrm{Hg} \\
\text { b Pulmonary capillary wedge pressure (PCWP) no more than } \\
15 \mathrm{~mm} \mathrm{Hg} \\
\text { c PVR more than } 3 \text { Wood units }{ }^{\mathrm{b}}\end{array}$ & $\begin{array}{l}8 \text { Clinically significant bleeding episode within the previous } \\
6 \text { months, or any other condition that would either } \\
\text { jeopardise subject safety and/or interfere with } \\
\text { interpretation of assessments }\end{array}$ \\
\hline
\end{tabular}

9 Echocardiography with evidence of clinically normal left ventricular function, absence of left-sided heart disease and unrepaired congenital heart disease

10 Ventilation perfusion lung scan, high-resolution computerised tomography scan of the chest and/or pulmonary angiography consistent with the diagnosis of $\mathrm{PAH}$

11 Pulmonary function tests conducted within previous 9 months demonstrating:

a Total lung capacity at least $60 \%$

b $\mathrm{FEV}_{1} / \mathrm{FVC}$ ratio at least $50 \%$
9 History of ischaemic heart disease within the previous 6 months of screening, or history of left-sided myocardial disease as evidenced by a PCWP greater than $15 \mathrm{~mm} \mathrm{Hg}$ or left ventricular ejection fraction less than $40 \%$

10 Uncontrolled systemic hypertension as evidenced by: a Systolic blood pressure above $160 \mathrm{~mm} \mathrm{Hg}$ b Diastolic blood pressure above $100 \mathrm{~mm} \mathrm{Hg}$

11 Musculoskeletal disorder or other disease that would limit ambulation or was connected to a machine that was not portable

12 Unstable psychiatric condition or any condition which would constitute an unacceptable risk to subject safety

13 Any investigational drug, investigational device in place or participation in an investigational study 30 days prior to screening

Entry criteria taken from the latest protocol version. ${ }^{a}$ Subjects who had administered inhaled prostacyclins prior to entry were now permitted provided usage ceased prior to enrolment. Due to the short wash-out period of these agents, their use prior to study enrolment was believed to have no impact on efficacy outcomes of the study. ${ }^{b}$ Study-defined timelines for pre-screening right heart catheter was extended from 4 to 8 weeks. Little or no change in parameters was expected over this extended period, and this timeline was believed to be more ethical for study subjects. 


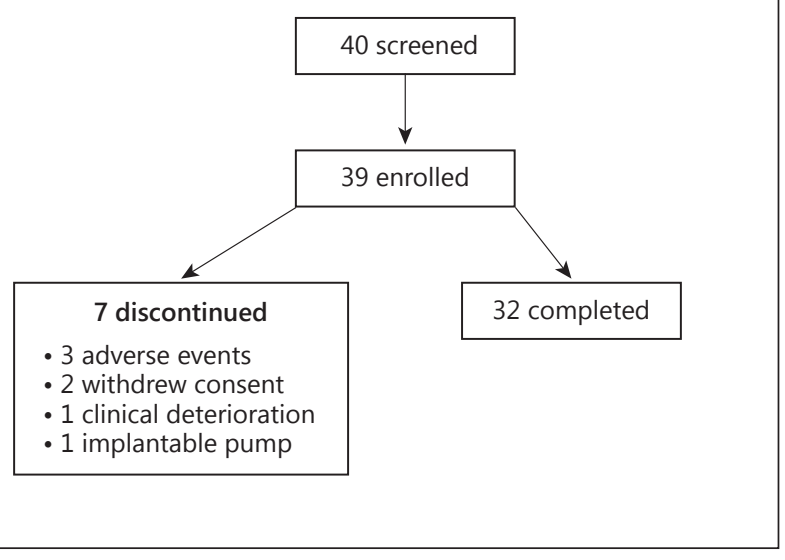

Fig. 1. Flowchart of study patients.

1 World Health Organisation (WHO) functional class (FC) II

2 6MWD greater than $400 \mathrm{~m}$ (or increase of more than $30 \mathrm{~m}$ if baseline 6MWD was greater than $400 \mathrm{~m}$ or if $400 \mathrm{~m}$ could not be reached)

3 Tricuspid annular plane systolic excursion (TAPSE) as measured by echocardiography greater than $2 \mathrm{~cm}$. Patients achieving one or more goals were considered to be treatment responders.

\section{Outcome Measures and Safety}

The primary objective to evaluate safety and tolerability was assessed throughout the study by monitoring adverse events (AEs), vital signs, severity of PAH symptoms (including fatigue, dyspnoea, oedema, dizziness, syncope, chest pain and orthopnoea) and physical examination. Overall tolerability of the rapid up-titration regimen was quantified by assessing the number of subjects who remained on treprostinil therapy for 16 weeks without experiencing a treprostinil-related serious AE (SAE).

The secondary efficacy endpoints included the changes from baseline to week 16 in exercise capacity (assessed using the 6MWD [13] and the Borg dyspnoea score), N-terminal pro-brain natriuretic peptide (NT pro-BNP) plasma concentration, WHO-FC, TAPSE and tricuspid regurgitant jet velocity (TRJV) (assessed by echocardiography), symptoms of $\mathrm{PAH}$, and cardiopulmonary haemodynamics measured by right heart catheterisation (RHC). Subject quality of life was assessed using the Cambridge Pulmonary Hypertension Outcome Review (CAMPHOR) questionnaire.

\section{Statistical Analysis}

The study population was defined as all subjects enrolled into the study. In general, the data were summarised by scheduled assessment. For continuous variables, the summary statistics included the mean, standard deviation, standard error, median, lower and upper quartile, and minimum and maximum values. For the purposes of describing the difference between baseline and followup assessments, $p$ values from Wilcoxon signed-rank test (for continuous variables) were included, but were not intended to test formal hypotheses. All values that were missing or deemed un-

Rapid Dose Titration of Subcutaneous

Treprostinil in $\mathrm{PAH}$
Table 2. Summary of demographic and other baseline characteristics

\begin{tabular}{lc}
\hline Baseline parameter & $\begin{array}{c}\text { Baseline value/ } \\
\text { number }(\mathrm{n}=39)\end{array}$ \\
\hline Age, years & \\
Mean (median) & $52.7(50)$ \\
Range & $25-82$ \\
Gender, $\mathrm{n}(\%)$ & \\
Female & $29(74.4)$ \\
Male & $10(25.6)$ \\
PAH aetiology, n (\%) & $39(100)$ \\
Idiopathic/heritable & \\
Background oral PAH therapy, $\mathrm{n}(\%)$ & $1(2.6)$ \\
None & $1(2.6)$ \\
ERA only & $2(5.1)$ \\
PDE-5 inhibitor only & $35(89.7)$ \\
ERA and PDE-5 inhibitor & \\
Baseline 6MWD, m & $355 \pm 93.1$ \\
Mean \pm SD & $163.0-547.0$ \\
Range & $352(288.0,423.0)$ \\
Median (Q1, Q3) & \\
Borg dyspnoea score (1-10) & $4.5 \pm 1.9$ \\
Mean \pm SD & $5.0(3.0,6.0)$ \\
Median (Q1, Q3) & \\
WHO-FC, $\mathrm{n}(\%)$ & $33(84.6)$ \\
II & \\
III & \\
&
\end{tabular}

6MWD = Six-min walk distance; ERA = endothelin receptor antagonist; $\mathrm{PAH}=$ pulmonary arterial hypertension; $\mathrm{PDE}-5=$ phosphodiesterase-5; SD = standard deviation; $\mathrm{WHO}=$ World Health Organization; Q1 = first quartile; Q3 = third quartile.

known were omitted from any analysis. No pre-defined co-variates were used in the analysis of the data.

\section{Ethical Standards}

The study was conducted in compliance with Good Clinical Practice guidelines and in accordance with the principles defined in the amended Declaration of Helsinki. The protocol was approved by the German regulatory authority (BfArM) and the central and local ethics committees of the Universities of Heidelberg, Cologne, Dresden, Regensburg, Leipzig, Munich and Saarbrucken, and of the medical council Hamburg, Munich and Dusseldorf. Written informed consent was obtained from all subjects prior to the conduct of any study-specific activities.

\section{Results}

\section{Baseline Characteristics and Patient Disposition}

Patient disposition and baseline demographics are summarised in figure 1 and table 2, respectively. A total of 40 subjects were screened for the study. Thirty-nine 
Table 3. AEs experienced by at least $20 \%$ of patients

\begin{tabular}{lcc}
\hline Preferred term & $\begin{array}{l}\text { Subjects, } \mathrm{n}(\%) \\
(\mathrm{n}=39)\end{array}$ & Events, $\mathrm{n}$ \\
\hline Any adverse event & $39(100)$ & 374 \\
Infusion site pain & $38(97.4)$ & 39 \\
Diarrhoea & $30(76.9)$ & 30 \\
Headache & $27(69.2)$ & 29 \\
Nausea & $20(51.3)$ & 20 \\
Vomiting & $15(38.5)$ & 16 \\
Infusion site erythema & $10(25.6)$ & 10 \\
Dyspnoea & $9(23.1)$ & 9 \\
Pain in jaw & $9(23.1)$ & 9 \\
Dizziness & $8(20.5)$ & 8 \\
Vertigo & $8(20.5)$ & 8 \\
\hline
\end{tabular}

subjects fulfilled the entry criteria and were enrolled and commenced on SC treprostinil therapy. Seven subjects (18\%) prematurely terminated the study before completion of the 16-week treatment period: 3 withdrew due to treatment-related AEs (infusion site pain, diarrhoea and nausea), 2 withdrew consent, 1 discontinued due to clinical deterioration, and 1 subject transitioned to IV treprostinil and was withdrawn from the study.

The proportion of female subjects (74\%) was almost three times that of the males $(26 \%)$ enrolled. Thirty-five subjects (90\%) were on dual oral background therapy (PDE-5 inhibitor and ERA), 3 subjects were on monotherapy (2 subjects on a PDE- 5 inhibitor, 1 on an ERA) and 1 subject was treatment naïve. The median baseline 6MWD was $352 \mathrm{~m}$ with a median Borg dyspnoea score of 5.0. The majority of subjects $(33 / 39 ; 85 \%)$ were in WHOFC III, with the remainder $(6 / 39 ; 15 \%)$ in WHO-FC II.

\section{Primary Objective: Safety and Tolerability}

AEs experienced by at least $20 \%$ of the patients are outlined in table 3. A total of 374 AEs were recorded. All subjects experienced at least one event during the study. The most frequently recorded AE reported by $38 / 39$ subjects (97\%) was infusion site pain. Infusion site pain was reasonably well tolerated, and was associated with study drug discontinuation in only $3(8 \%)$ subjects. In general, AEs were well tolerated, with symptomatic treatments prescribed at the discretion of the investigators. Opioids were prescribed 35 times in the form of oral treatment, including morphine on five occasions. Mainly hydromorphone and oxycodone were used. Most of the patients received non-steroidal analgesics (e.g., ibuprofen,

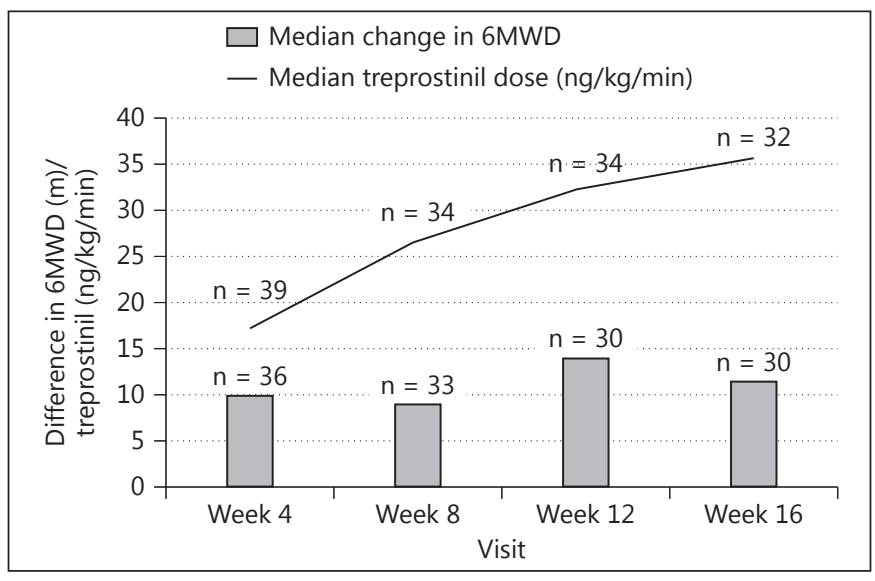

Fig. 2. Change of median $6 \mathrm{MWD}$ and treprostinil dosage throughout the study.

paracetamol, diclofenac). There were 27 SAEs reported by $11 / 39$ subjects $(28 \%)$. Thirteen SAEs, which occurred in $7 / 39$ subjects ( $18 \%$ ), were considered to be related to treprostinil. Three of those related SAEs, diarrhoea, nausea and infusion site pain, occurred in more than 1 subject.

\section{Secondary Objective: Efficacy}

Exercise Capacity

Table 4 provides a summary of the median 6MWD together with the median dose of treprostinil achieved by all patients remaining on therapy at each time point. The effects seen during the treatment period are illustrated in figure 2. The results of the Wilcoxon signed-rank test indicate that the week 12 and week 16 6MWD ranks were statistically significantly higher than the baseline 6MWD ranks ( $\mathrm{p}=0.0409$ and $\mathrm{p}=0.0086$, respectively). Median changes from baseline of 14.0 and $11.5 \mathrm{~m}$ were observed at weeks 12 and 16, respectively. This indicates that there was an improvement in exercise capacity for the 32 subjects $(82 \%)$ who were able to tolerate the rapid up-titration of SC treprostinil therapy to $30 \mathrm{ng} / \mathrm{kg} / \mathrm{min}$ and completed the 16-week treatment period. The targeted dosage of at least $30 \mathrm{ng} / \mathrm{kg} / \mathrm{min}$ was achieved by $25(78 \%)$ of the 32 patients who completed the 16 -week treatment period of the study.

\section{Other Clinical Parameters}

There were beneficial and statistically significant changes in other important clinical parameters assessed during the 16-week treatment period (table 5). A median change from baseline in plasma NT pro-BNP of $-182 \mathrm{pg} /$ 
Table 4. Summary of 6MWD and treprostinil dose rate achieved during the study

\begin{tabular}{lllll}
\hline Visit & $\begin{array}{l}\text { Week 4 } \\
(\mathrm{n}=36)\end{array}$ & $\begin{array}{l}\text { Week 8 } \\
(\mathrm{n}=33)\end{array}$ & $\begin{array}{l}\text { Week 12 } \\
(\mathrm{n}=30)\end{array}$ & $\begin{array}{l}\text { Week 16 } \\
(\mathrm{n}=30)\end{array}$ \\
\hline Median baseline 6MWD, m & 353 & 352 & 348 & 351 \\
$\quad$ Q1 & 291 & 294 & 288 & 294 \\
Q3 & 427 & 420 & 423 & 420 \\
Median visit 6MWD, m & 395 & 360 & 402 & 419 \\
$\quad$ Q1 & 297 & 300 & 320 & 309 \\
$\quad$ Q3 & 460 & 453 & 462 & 468 \\
Median change in 6MWD from baseline, $\mathrm{m}$ & 10 & 9 & 14 & 11.5 \\
p value & 0.0113 & 0.2368 & 0.0409 & 0.0086 \\
Treprostinil dose rate, ng/kg/min & & & & \\
$\quad$ Median & 17.2 & 26.8 & 32.6 & 35.7 \\
$\quad$ Q1 & 14.5 & 22.5 & 27.0 & 31.1 \\
Q3 & 22.4 & 30.7 & 36.2 & 41.0 \\
$\quad$ Patients, $\mathrm{n}^{\mathrm{a}}$ & 39 & 34 & 34 & 32 \\
\hline
\end{tabular}

$6 \mathrm{MWD}=$ Six-min walk distance; $\mathrm{Q} 1=$ first quartile; $\mathrm{Q} 3=$ third quartile. ${ }^{\mathrm{a}}$ Number of patients completing the given assessment at the visit outlined. $\mathrm{ml}$, and an improvement in WHO-FC at week $16 \mathrm{com}$ pared to baseline in $25 \%$ of subjects was observed. Only 2 patients $(6.3 \%)$ worsened, one from WHO-FC II to III, and the other from WHO-FC III to IV. Median changes from baseline in the cardiac index of $0.31 / \mathrm{min} / \mathrm{m}^{2}(\mathrm{p}<$ $0.0001)$ and PAPm of $-4.0 \mathrm{~mm} \mathrm{Hg}$ were associated with a median change from baseline in PVR index of $-2.7 \mathrm{~mm}$ $\mathrm{Hg} / \mathrm{min} / \mathrm{m}^{2} / \mathrm{l}(\mathrm{p}<0.0001)$, suggesting an overall improvement in cardiopulmonary haemodynamics. This was further supported by median changes from baseline to week 16 of $0.1 \mathrm{~cm}$ and $-0.3 \mathrm{~m} / \mathrm{sec}$ in the TAPSE and TRJV, respectively, which are consistent with an improvement in right ventricular performance. After 16 weeks, there was a significant improvement in patient outcome assessed by the CAMPHOR questionnaire $(\mathrm{p}=0.0040)$, which could also be seen in a significant improvement of the two subscales, Symptoms $(\mathrm{p}=0.0105)$ and Activity $(\mathrm{p}=0.0094)$. The CAMPHOR subscale score 'quality of life' also improved, although this was not statistically significant $(\mathrm{p}=$ 0.0845). There was no clear change in the severity of PAH symptoms recorded during the study. However, the overall effects observed during the study indicate that a rapid up-titration dosing regimen for SC treprostinil therapy administered to subjects with severe PAH can improve exercise capacity, functional performance and cardiopulmonary haemodynamics.

\section{Treatment Goals}

Analysis of the pre-defined, protocol-specified treatment goals achieved by those patients who remained on treprostinil therapy for the 16-week treatment period of the study is summarised in table 6 . The number of pa- tients who achieved each of the individual criteria is shown together with the number of patients that met multiple goals. In line with the criteria for defining a treatment responder, a total of 20/39 (51\%) of the enrolled subjects achieved at least one pre-defined treatment goal on SC treprostinil therapy when administered in accordance with the rapid up-titration dosing regimen. In 18 of the 20 aforementioned patients, achievement of treatment goals was due to improvement of clinical parameters during the study: the remaining 2 subjects remained WHO-FC II from baseline through to week 16.

\section{Discussion}

To the best of our knowledge, this is the first prospective multicentre study investigating the effect of rapid dose titration of SC treprostinil, together with a proactive approach to infusion site management and RHC performed at baseline and after 16 weeks. Rapid dose titration was generally well tolerated and led to a clinically effective dosage, as demonstrated by an improvement in exercise capacity and haemodynamics during the 16week study period. A rapid dose titration and proactive infusion site management may therefore improve the management of this therapy and contribute to an improved treatment outcome.

Clinically effective dosages could be reached by rapid dose titration and were generally tolerable. Compared to the rapid dose titration scheme used by Skoro-Sajer et al. [3], the mean dosages achieved after 4, 8 and 12 weeks were considerably higher in this study, with $32.0 \mathrm{com}$ - 
Table 5. Summary of changes in clinical assessments from baseline

\begin{tabular}{|c|c|c|c|c|}
\hline Parameter & Baseline & Week 16 & $\begin{array}{l}\text { Change from } \\
\text { baseline }\end{array}$ & $\mathrm{p}$ value \\
\hline \multicolumn{5}{|c|}{ Borg dyspnoea score $(1-10)$} \\
\hline Median & 5.0 & 3.5 & 0.0 & \multirow[t]{4}{*}{0.1937} \\
\hline Q1 & 3.0 & 3.0 & -1.0 & \\
\hline Q3 & 6.0 & 5.0 & 0.5 & \\
\hline Patients, $\mathrm{n}$ & 39 & $30^{\mathrm{a}}$ & & \\
\hline \multicolumn{5}{|c|}{ WHO-FC, n (\%) } \\
\hline II & $6(15.4)$ & $12(30.8)$ & II-II: 4 (12.5) & \multirow[t]{5}{*}{ n.a. } \\
\hline III & $33(84.6)$ & $19(48.7)$ & II-III: 1 (3.1) & \\
\hline \multirow[t]{3}{*}{ IV } & \multirow[t]{3}{*}{$0(0)$} & \multirow[t]{3}{*}{$1(3)$} & III-II: 8 (25.0) & \\
\hline & & & III-III: 18 (56.3) & \\
\hline & & & III-IV: 1 (3.1) & \\
\hline Patients, $\mathrm{n}$ & 39 & $32^{\mathrm{a}}$ & 32 & \\
\hline \multicolumn{5}{|c|}{ NT pro-BNP, pg/ml $(\mathrm{n}=32)$} \\
\hline Median & 999 & 702 & -182 & \multirow[t]{3}{*}{0.0081} \\
\hline Q1 & 522 & 376 & -985 & \\
\hline Q3 & 2,538 & 1,377 & 51 & \\
\hline \multicolumn{5}{|c|}{ Haemodynamics } \\
\hline \multicolumn{5}{|c|}{ PAPm, mm Hg $(\mathrm{n}=29)^{\mathrm{a}}$} \\
\hline Median & 52.0 & 49.0 & -4.0 & \multirow{3}{*}{0.1115} \\
\hline Q1 & 47 & 44 & -10 & \\
\hline Q3 & 62 & 60 & 1 & \\
\hline \multicolumn{5}{|c|}{ Cardiac index, $1 / \mathrm{min} / \mathrm{m}^{2}(\mathrm{n}=29)^{\mathrm{a}}$} \\
\hline Median & 2.2 & 2.6 & 0.3 & \multirow[t]{3}{*}{$<0.0001$} \\
\hline Q1 & 2 & 2 & 0 & \\
\hline Q3 & 3 & 3 & 1 & \\
\hline \multicolumn{5}{|c|}{ PVRI, $\mathrm{mm} \mathrm{Hg} / \mathrm{min} / \mathrm{m}^{2} / \mathrm{l}(\mathrm{n}=29)^{\mathrm{a}}$} \\
\hline Median & 20.7 & 16.3 & -2.7 & \multirow[t]{3}{*}{$<0.0001$} \\
\hline Q1 & 16 & 12 & -6 & \\
\hline Q3 & 25 & 22 & -1 & \\
\hline \multicolumn{5}{|c|}{ SVRI, $\mathrm{mm} \mathrm{Hg} / \mathrm{min} / \mathrm{m}^{2} / \mathrm{l}(\mathrm{n}=25)^{\mathrm{a}}$} \\
\hline Median & 36.1 & 29.7 & -5.5 & \multirow[t]{3}{*}{$<0.0001$} \\
\hline Q1 & 31 & 25 & -8 & \\
\hline Q3 & 42 & 36 & -2 & \\
\hline \multicolumn{5}{|c|}{ Echocardiography } \\
\hline \multicolumn{5}{|c|}{ TAPSE, $\mathrm{cm}$} \\
\hline Median & 1.6 & 1.8 & 0.1 & \multirow[t]{4}{*}{0.0174} \\
\hline Q1 & 1.4 & 1.6 & 0.0 & \\
\hline Q3 & 1.9 & 2.0 & 0.3 & \\
\hline Patients, $\mathrm{n}$ & 39 & $31^{\mathrm{a}}$ & & \\
\hline \multicolumn{5}{|l|}{$\mathrm{TRJV}, \mathrm{m} / \mathrm{s}$} \\
\hline Median & 4.40 & 3.90 & -0.3 & \multirow[t]{4}{*}{0.0068} \\
\hline Q1 & 4.00 & 3.40 & -0.6 & \\
\hline Q3 & 4.74 & 4.53 & 0.1 & \\
\hline Patients, $\mathrm{n}$ & 38 & $27^{\mathrm{a}}$ & & \\
\hline
\end{tabular}

$\mathrm{WHO}=$ World Health Organisation; NT pro-BNP $=$ N-terminal probrain natriuretic peptide; $\mathrm{PAPm}=$ mean pulmonary artery pressure; PVRI = pulmonary vascular resistance index; SVRI = systemic vascular resistance index; TAPSE = tricuspid annular plane systolic excursion; TRJV = tricuspid regurgitant jet velocity.

${ }^{\text {a }}$ Number of patients completing each assessment at week 16.

pared to $20.3 \mathrm{ng} / \mathrm{kg} / \mathrm{min}$ after 12 weeks. AEs, especially infusion site pain, did not differ substantially from previous studies, even though higher dosages were achieved within the 16-week study period.
Table 6. Treatment goals achieved at the end of the study $(n=39)$

\begin{tabular}{ll}
\hline & Subjects, $\mathrm{n}(\%)$ \\
\hline Treatment goal & \\
Completed 16-week treatment period & $32(82)$ \\
WHO-FC II & $12(31)^{\mathrm{a}}$ \\
6MWD greater than $400 \mathrm{~m}$ & $11(28)^{\mathrm{b}}$ \\
TAPSE greater than $2 \mathrm{~cm}$ & $6(15)^{\mathrm{c}}$ \\
Number of treatment goals achieved & \\
0 & $19(49)$ \\
1 or more goals & $20(51)$ \\
1 & $12(31)$ \\
2 & $7(18)$ \\
3 & $1(3)$ \\
\hline
\end{tabular}

${ }^{a}$ Four subjects were WHO-FC II at baseline and remained WHO-FC II at week 16, b Three subjects had a baseline walk greater than $400 \mathrm{~m}$, all increased by more than $30 \mathrm{~m}$ at week 16 , ${ }^{c}$ Two subjects had a TAPSE of greater than $2 \mathrm{~cm}$ at baseline and retained a value of greater than $2 \mathrm{~cm}$ at week 16 .

Infusion site pain occurred in $97 \%$ of the patients, which is comparable to the rate reported by Barst et al. [6], but higher than the rate of $82 \%$ that was detected by Lang et al. [5] and by Skoro-Sajer et al. [3]. In our patient cohort, the finding of a significantly lower incidence (58\%) of infusion site pain when using a rapid dose titration regimen [3] was not confirmed. The study by SkoroSajer et al. [3] only included 12 patients performing rapid dose titration, which may have limited the reliability of the results. In addition, only site pain experienced by patients from Vienna was systematically assessed by a visual analogue scale, which may have led to less frequent reporting of site pain compared to a systematic assessment in all of our study patients. Furthermore, in up to $20 \%$ of patients investigated by Skoro-Sajer et al. [3], infusion site pain required drug interruption. In our patient cohort, only $8 \%$ of patients discontinued treatment due to infusion site pain, which is comparable to the frequency of discontinuation due to site pain reported by Barst et al. [6]. In that study, out of a cohort of 860 patients, 196 discontinued treatment due to infusion site pain (23\%) during a mean duration of exposure of $2.6 \pm 0.8$ years. Within the first 6 months, $50 \%$ of the patients who discontinued due to site pain had already stopped treatment and had a comparable dropout rate to our cohort after 16 weeks of treatment [6]. Different pain treatments, including local/topical options and systemic analgesics, are available and may be used for different intensities of infusion site pain [10]. In our cohort, mostly non-opioid an- 
algesics were used. However, opioids were also prescribed on 35 occasions throughout the study, including morphine in 5 cases. Up to now, little is known about the best point in time that pain treatment should begin. Whether a prophylactic pain management regimen that coincides with the start of the infusion may influence the intensity of infusion site pain and the overall tolerability of the treatment remains to be investigated. Other side effects included systemic adverse reactions typical of those associated with prostacyclin use, such as diarrhoea, headache, nausea and vomiting.

Our study results are consistent with previous reports of clinical improvements in 6MWD $[4,5,14]$ and haemodynamics [4] measured by RHC with a significant improvement of cardiac index and reduction of PVR. More than half of the patients in our cohort (51\%) were considered to be treatment responders who achieved at least one of the pre-defined treatment goals at the end of the study period. Out of 20 patients showing a treatment response, 18 improved until the end of the 16-week study period to reach at least one treatment goal, whilst 2 remained stable from baseline. It is important to recall that these subjects had severe PAH, with $85 \%$ in WHO-FC III at baseline. Furthermore, the majority of patients enrolled (90\%) were established on dual oral background therapy, and the additional treatment response following 16 weeks of SC treprostinil indicates the effectiveness of a triple combination intervention. As early treatment for PAH improves long-term outcomes, the impact of such a triple therapy combination targeting the individual therapeutic targets of vascular pathology merits further investigation.

The main limitations of our study are the small sample size and the study duration of 16 weeks. The patients of our study cohort were hospitalised for at least $72 \mathrm{~h}$ for the initial up-titration phase every $12 \mathrm{~h}$. However, we assume that rapid, patient-triggered up-titration may also be feasible in an ambulatory setting.

As this study was intended to investigate the safety and tolerability of a rapid dose titration regimen, the main focus was on the titration phase. Thus, a long-term follow-up was not performed. As the titration phase occurs principally during the first 3-4 months of treatment, the study allowed evaluation of safety and tolerability over the most crucial time period. Patients are more likely to discontinue SC treprostinil during the initiation of therapy [6]. All patients who completed the 16-week study period tolerated SC treprostinil well. Therefore, a significant deviation from discontinuation rates due to medication intolerance already reported in the literature is not expected.

Rapid Dose Titration of Subcutaneous Treprostinil in $\mathrm{PAH}$
A further option to avoid SC infusion site pain and minimise the risk of blood stream infections associated with the presence of an in-dwelling central venous catheter is to deliver IV treprostinil via an implanted infusion pump device, which has been successfully used both in neurology for intrathecal or epidural therapy and for the treatment of patients with PAH [15-17]. The application, safety and tolerability of implantable pumps for IV treprostinil therapy in PAH patients is currently being investigated.

\section{Conclusion}

Though many new agents have been developed for disease-specific therapy of $\mathrm{PAH}$, prostanoids remain one of the most potent treatment options associated with improvement of exercise capacity, PAH symptoms and cardiopulmonary haemodynamics. In this study, rapid dose titration led to earlier attainment of clinically effective dosages of SC treprostinil than is usually achieved during the titration phase, as described by the current European labelling for treprostinil [18]. In combination with a proactive approach to infusion site pain management, an accelerated titration scheme can be well tolerated, whilst more rapidly improving exercise capacity and haemodynamics in patients with severe PAH already established on dual oral background therapy. A rapid dose titration regimen together with proactive infusion site pain management may therefore improve the management of this therapy and contribute to a better treatment outcome.

\section{Acknowledgements}

The study was funded by United Therapeutics Limited.

\section{Financial Disclosure and Conflicts of Interest}

E.G. reports research grants to his institution from United Therapeutics during the conduct of the study; received speaker fees and honoraria as advisory board member from Bayer, Actelion, GSK and United Therapeutics.

N.B. reports research grants to her institution from United Therapeutics during the conduct of the study; received speaker fees from Bayer and Actelion.

T.J.L. reports grants and non-financial support from United Therapeutics during the conduct of the study; personal fees and non-financial support from Actelion, personal fees and non-financial support from Bayer, personal fees and non-financial support from GlaxoSmithKline, personal fees and non-financial support 
from Pfizer, personal fees from United Therapeutics, outside the submitted work.

U.K. reports research grants to his institution from United Therapeutics during the conduct of the study.

H.K. reports research grants to his institution from United Therapeutics during the conduct of the study; reports personal fees from Pfizer, grants and personal fees from GSK, personal fees from Bayer, personal fees from United Therapeutics, grants and personal fees from Actelion, outside the submitted work.

C.N. reports research grants to his institution from United Therapeutics during the conduct of the study.

H.W. reports study fees from United Therapeutics during the conduct of the study; grants and personal fees from Actelion, personal fees from Bayer, personal fees from GSK, personal fees from Pfizer, personal fees from Biotest, personal fees from Roche, outside the submitted work.

M.H. reports grants from Actelion, honoraria for lectures from Actelion, Bayer Healthcare, Berlin Chemie, Boehringer Ingelheim, GSK, Novartis, Pfizer, honoraria for advisory board activities from Actelion, Bayer Healthcare, GSK, during the conduct of the study; and participation in clinical trials of Actelion, Bayer, GSK, Pfizer, United Therapeutics.

H.-J.S. reports personal fees from Actelion Deutschland $\mathrm{GmbH}$ and personal fees from GlaxoSmithKline GmbH \& Co KG, outside the submitted work.
M.H. reports research grants to his institution from United Therapeutics during the conduct of the study; reports personal fees for lectures and for advisory board activity and congress travel support from Actelion, AstraZeneca, Bayer, GlaxoSmithKline, Pfizer and Novartis outside the submitted work.

A.T. is an employee of the sponsor.

M.P. was an employee of the sponsor during the conduct of the study.

R.G. is an employee of the sponsor.

B.E. has nothing to disclose.

F.G. reports research grants to his institution from United Therapeutics during the conduct of the study; he has received remunerations for lectures and advisory boards from Actelion, Bayer and GSK His institution has received research grants from Actelion, Bayer, Novartis, Pfizer and United Therapeutics.

T.V. received honoraria for lectures from Actelion, GSK, UT, Vifor, Bayer; grants for participation in clinical trials from Bayer, UT, Actelion, GSK, and is an employee of Bayer.

S.R. reports research grants to his institution from United Therapeutics during the conduct of the study; he has received remunerations for lectures and advisory boards from Actelion, Bayer, Gilead, GSK, Novartis, Pfizer and United Therapeutics. His institution has received research grants from Actelion, Bayer, Novartis, Pfizer and United Therapeutics.

\section{References}

1 Gomberg-Maitland M, Olschewski H: Prostacyclin therapies for the treatment of pulmonary arterial hypertension. Eur Respir J 2008; 31:891-901.

-2 Barst RJ, Rubin LJ, Long WA, McGoon MD, Rich S, Badesch DB, et al: A comparison of continuous intravenous epoprostenol (prostacyclin) with conventional therapy for primary pulmonary hypertension. N Engl J Med 1996;334:296-301.

3 Skoro-Sajer N, Lang IM, Harja E, Kneussl MP, Sing WG, Gibbs SJ: A clinical comparison of slow- and rapid-escalation treprostinil dosing regimens in patients with pulmonary hypertension. Clin Pharmacokinet 2008;47: 611-618.

-4 Simonneau G, Barst RJ, Galie N, Naeije R, Rich S, Bourge RC, et al: Continuous subcutaneous infusion of treprostinil, a prostacyclin analogue, in patients with pulmonary arterial hypertension: a double-blind, randomized, placebo-controlled trial. Am J Respir Crit Care Med 2002;165:800-804.

5 Lang I, Gomez-Sanchez M, Kneussl M, Naeije R, Escribano P, Skoro-Sajer N, et al: Efficacy of long-term subcutaneous treprostinil sodium therapy in pulmonary hypertension. Chest 2006;129:1636-1643.

-6 Barst RJ, Galie N, Naeije R, Simonneau G, Jeffs R, Arneson C, et al: Long-term outcome in pulmonary arterial hypertension patients treated with subcutaneous treprostinil. Eur Respir J 2006;28:1195-1203.
7 Sadushi-Kolici R, Skoro-Sajer N, Zimmer D, Bonderman D, Schemper M, Klepetko W, et al: Long-term treatment, tolerability, and survival with sub-cutaneous treprostinil for severe pulmonary hypertension. J Heart Lung Transplant 2012;31:735-743.

-8 White RJ, Levin Y, Wessman K, Heininger A, Frutiger K: Subcutaneous treprostinil is well tolerated with infrequent site changes and analgesics. Pulm Circ 2013;3:611-621.

-9 Benza RL, Gomberg-Maitland M, Naeije R, Arneson CP, Lang IM: Prognostic factors associated with increased survival in patients with pulmonary arterial hypertension treated with subcutaneous treprostinil in randomized, placebo-controlled trials. J Heart Lung Transplant 2011;30:982-989.

10 Mathier MA, McDevitt S, Saggar R: Subcutaneous treprostinil in pulmonary arterial hypertension: practical considerations. J Heart Lung Transplant 2010;29:1210-1217.

11 Kimura M, Tamura Y, Takei M, Yamamoto T, Ono T, Kuwana M, et al: Rapid initiation of intravenous epoprostenol infusion is the favored option in patients with advanced pulmonary arterial hypertension. PLoS One 2015;10:e0121894.

12 Tokunaga N, Ogawa A, Ito H, Matsubara H: Rapid and high-dose titration of epoprostenol improves pulmonary hemodynamics and clinical outcomes in patients with idiopathic and heritable pulmonary arterial hypertension. JCardiol DOI: 10.1016/j.jjcc.2015.11.012.
13 American Thoracic Society, Committee on Proficiency Standards for Clinical Pulmonary Function Laboratories: ATS statement: guidelines for the six-minute walk test. Am J Respir Crit Care Med 2002;166:111-117.

14 Rubenfire M, McLaughlin VV, Allen RP, Elliott G, Park MH, Wade M, et al: Transition from IV epoprostenol to subcutaneous treprostinil in pulmonary arterial hypertension: a controlled trial. Chest 2007;132:757-763.

15 Dario A, Scamoni C, Picano M, Fortini G, Cuffari S, Tomei G: The infection risk of intrathecal drug infusion pumps after multiple refill procedures. Neuromodulation 2005;8: 36-39.

16 Ewert R, Halank M, Bruch L, Ghofrani HA: A case series of patients with severe pulmonary hypertension receiving an implantable pump for intravenous prostanoid therapy. Am J Respir Crit Care Med 2012;186:1196-1198.

-17 Bourge RC, Waxman AB, Gomberg-Maitland M, Shapiro S, Tarver J, Zwicke D, Feldman J, Chakinala M, Frantz R, Torres F, Cerkvenik J, Morris M, Thalin M, Peterson L, Rubin L: Treprostinil administered using a fully implantable programmable intravascular delivery system: results of the delivery for $\mathrm{PAH}$ trial. Chest 2014;146:862A.

18 United Therapeutics Corp: United Therapeutics Summary of Product Characteristics. 22. Remodulin $1 \mathrm{mg} / \mathrm{ml}$ solution for infusion. August 2014. 